\title{
Espectrorradiometria de reflectância de rochas carbonáticas na região do infravermelho de ondas curtas
}

\author{
Sandra Aparecida Pedrosa ${ }^{1,2}$, Paulo Roberto Meneses $^{3}$ \& Adriana Chatack Carmelo ${ }^{3}$
}

\begin{abstract}
Resumo No presente trabalho teve-se como objetivo estudar o comportamento espectral de rochas carbonáticas da Formação Sete Lagoas do Grupo Bambuí, da região da Serra do Ramalho, no estado da Bahia. Foram realizadas em laboratório medidas de reflectância de dezesseis amostras de calcários e quatro de dolomitos no infravermelho de ondas curtas (1300-2000 nm), utilizando-se o espectrorradiômetro PIMA. A análise dos espectros foi acompanhada por observações detalhadas de campo, descrições petrográficas de lâminas, análise química dos compostos maiores e de teores de matéria orgânica, para o seguinte grupo de rochas carbonáticas: calcilutitos, calcarenitos, calcários oolíticos, calcários argilosos e dolomitos. Com base na análise espectral observou-se que as posições da principal feição de absorção do íon $\mathrm{CO}_{3}^{-2}$ nos calcilutitos, calcarenitos e calcários argilosos são muito próximas e tem seu pico centrado em média em $2336 \mathrm{~nm}$, enquanto nos calcários oolíticos está centrada em $2332 \mathrm{~nm}$. A principal diferença espectral dos calcários é o aumento da profundidade das feições de absorção com o aumento da granulometria ou a presença de argilominerais, e a diminuição da absorção diante da presença de matéria orgânica. Os dolomitos apresentam espectros semelhantes aos dos calcários, com a diferença que a feição principal de absorção está centrada em $2321 \mathrm{~nm}$. Feições secundárias de absorção estão centradas próximas a 2140 $\mathrm{nm}, 1930 \mathrm{~nm}$, e $1430 \mathrm{~nm}$. A presença de matéria orgânica, mesmo em quantidade inferior a 0,1\% causa redução na profundidade das feições de absorção, ou mesmo seu mascaramento, para todos os litotipos estudados.
\end{abstract}

Palavras-chave: reflectância, espectrorradiometria, carbonatos.

\begin{abstract}
Spectroradiometry reflectance of carbonate rocks in the infrared shortwave. This work aims to study the spectral behavior of carbonaceous rocks from Sete Lagoas Formation of Group Bambuí, in the region of Serra do Ramalho, state of Bahia. Measurements of reflectance in laboratory were made for sixteen samples of limestones and four dolomites in shortwave infrared (1300 to $2500 \mathrm{~nm})$, using a spectroradiometer PIMA. The analysis of the spectra was accompanied by detailed observations of field, petrographic descriptions, chemical analysis of major compounds and organic matter content, to the following group of carbonate rocks: lime mudstone, calcarenites, oolitic limestone, argillaceous limestone, and dolomite. Based on spectral analysis it is observed that the position of the main absorption feature of ion $\mathrm{CO}_{3}{ }^{-2}$ in lime mudstone, argillaceous limestones and calcarenites has their peak centered on average $2336 \mathrm{~nm}$ while the oolitic limestone is centered on $2332 \mathrm{~nm}$. The main differences between the features of the limestones are marked by increased depth of absorption features, with increasing particle size or the presence of clay and a decrease of absorption with the presence of organic matter. The dolomites have its main feature centered on average $2321 \mathrm{~nm}$. Secondary absorptions bands occur near $2140 \mathrm{~nm}, 1930 \mathrm{~nm}$, and $1430 \mathrm{~nm}$. The presence of organic matter even in quantities of less than $0.1 \%$ cause reduction in the depth of absorption feature or even its almost total suppression for all rocks studied.
\end{abstract}

Keywords: reflectance, spectroradiometry, carbonate.

INTRODUÇÃO A interpretação de imagens de sensores remotos fundamenta-se, basicamente, na análise do comportamento da reflectância espectral dos materiais no intervalo de comprimento de onda do visível ao infravermelho de ondas curtas (400 a $2500 \mathrm{~nm})$. Para isso, usa-se a espectrorradiometria de reflectância que é uma técnica que tem a função de medir em diferentes comprimentos de onda a energia eletromagnética refletida da superficie dos materiais e representá-la na forma de um gráfico que se denomina de curva de re- flectância espectral. O poder analítico desta técnica é que a informação espectral se correlaciona diretamente com a composição química e a estrutura cristalina dos minerais, e deste modo é indicativa para se determinar a composição mineralógica de uma rocha. Com o crescente interesse para os sensores hiperespectrais, bibliotecas espectrais de minerais, abertamente disponíveis para consultas, passaram a ser uma fonte de referência e de suporte para a interpretação de imagens. Contudo, essas bibliotecas são melhor aproveitadas para estudos

1 - Departamento Nacional de Produção Mineral, Brasília (DF), Brasil. E-mail: sandra.pedrosa@dnpm.gov.br

2 - Universidade de Brasília, Campus Universitário Darcy Ribeiro, Instituto de Geociências, Programa de Pós-Graduação, Asa Norte, Brasília (DF), Brasil.

3 - Universidade de Brasília, Campus Universitário Darcy Ribeiro, Instituto de Geociências, Asa Norte, Brasília (DF), Brasil.

E-mail: pmeneses@unb.br; chatack@unb.br 
voltados à pesquisa mineral de minérios do que para uso na discriminação litológica, pelo fato de os dados espectrais de rochas serem mais complexos de obtenção e análise, por terem as rochas sempre a particularidade das variações petrográficas e texturais, de impurezas e de não homogeneidade. Porém, para alguns tipos litológicos, como as rochas hidrotermalizadas, fosforitos e carbonatos, os padrões de reflectância são bem característicos, por serem dominados pelos minerais primários da composição destas rochas. É o caso, por exemplo, das rochas carbonáticas, onde, essencialmente, os minerais calcita ou dolomita controlam a reflectância. Infelizmente, na literatura especializada em estudos espectrorradiométricos há poucas referências na pesquisa de rochas carbonáticas. Trabalhos como os de Hunt \& Salisbury (1971), Gaffey (1987), Crowley (1986) e Meneses (1986), demonstraram que é possível a partir dos espectros extrair várias informações acerca da composição de carbonatos na faixa do infravermelho de ondas curtas, de 1600 a $2500 \mathrm{~nm}$, tais como variações de granulometria, presença de impurezas minerais de argilas, sílica, sulfetos e de matéria orgânica, e determinar as variações composicionais primárias calcíticas e dolomíticas. Nos espectros, estas informações são identificadas por mudanças nas intensidades, localizações e formas das feições de absorções.

Os detalhados estudos espectrorradiométricos, realizados por Hunt \& Salisbury (1971) e Gaffey (1987), demonstraram que o grupo $\mathrm{CO}^{-2}{ }_{3}$ quando aparece isolado nos carbonatos com fórmula geral $\mathrm{MCO}_{3}$ de estrutura romboédrica (calcita, dolomita, rodocrosita, siderita, magnesita) e ortorrômbica (aragonita, cerussita) apresenta até cinco modos de vibração molecular, em média centradas em $2550 \mathrm{~nm}, 2350 \mathrm{~nm}$, $2160 \mathrm{~nm}, 2000 \mathrm{~nm}$ e $1850 \mathrm{~nm}$, que podem ser perturbados por absorções mais intensas que ocorrem em torno de $1400 \mathrm{~nm}$, ou $1900 \mathrm{~nm}$, devida à presença do grupo $\mathrm{OH}^{-}$ou de moléculas de água.

Neste trabalho teve-se como objetivo estudar o comportamento espectral de rochas calcárias e dolomíticas pertencentes à Formação Sete Lagoas do Grupo Bambuí, da região da Serra do Ramalho, no estado da Bahia, utilizando-se de medidas de reflectância de laboratório com o espectrorradiômetro PIMA. A análise dos espectros foi acompanhada por observações detalhadas de campo, descrições petrográficas de lâminas, análise química dos compostos maiores e de teores de matéria orgânica.

ÁREA DE PESQUISA As medidas espectrorradiométricas foram tomadas de amostras de rochas coletadas na região da serra do Ramalho, oeste da Bahia, onde ocorrem extensas exposições de rochas carbonáticas do Grupo Bambuí, livres de cobertura de solos e de vegetação. De interesse deste trabalho foram as rochas da Formação Sete Lagoas, que na área foi subdividida por Miranda et al. (1976), com trabalhos de mapeamentos de detalhe, em três subunidades (C1, C2 e C3), e posteriormente denominadas por Conceição Filho et al. (2003), respectivamente, de membros inferior, médio e superior (Fig. 1). O membro inferior está profundamen- te erodido, e constitui-se em uma superfície uniformemente plana revestida por solos e raros afloramentos. O membro médio foi o mais amostrado, por ser a unidade com maior área de exposição e variação faciológica, sendo constituído predominantemente por extensos afloramentos de calcários calcíticos. São afloramentos totalmente expostos, e apresentam uma marcante morfologia cárstica com forma de lápies. Dominam calcários de cor cinza escuro a preto, de granulação fina a grossa, apresentando-se maciços, laminados ou plaqueados, e comumente cortados por vênulas irregulares de calcita branca. Localmente, ocorrem calcários argilosos de cor cinza esverdeado, com níveis milimétricos a centimétricos de argilominerais, marcando um bandamento na rocha. Para o topo desta unidade intermediária ocorrem intercalações de calcarenitos com rochas de composição dolomítica de cor cinza claro. A continuidade desta gradação termina com o predomínio de dolomitos sobre os calcários. Este predomínio caracteriza o membro superior da Formação Sete Lagoas ou unidade C3, que é constituída predominantemente por dololutitos de cor cinza claro, de granulação fina, dolarenitos cinza claros a rosados, associados a brechas dolomíticas localmente cimentadas por fluorita e calcita.

FONTE DOS DADOS Foram utilizados neste estudo como base de dados de referência, mapas geológicos, análises petrográfica e geoquímica, e medidas espectrorradiométricas de amostras coletadas em campo. Os mapas geológicos utilizados na orientação para a coleta das amostras foram os do Projeto Fluorita na serra do Ramalho, nas escalas 1: 50.000 e 1: 2000 (Miranda et al. 1976). Os espectros de reflectância das amostras coletadas no campo foram obtidos em laboratório com o espectrorradiômetro PIMA (Portable Infrared Mineral Analyser), fabricado pela Integrated Spectronics Pty Ltd, que cobre a faixa do SWIR (1300 a $2500 \mathrm{~nm}) \mathrm{e}$ tem resolução espectral constante de $2 \mathrm{~nm}$. Para aquisição das curvas espectrais utilizou o programa PIMA SP Acquisition, versão 2.2 e para visualização e análise dos espectros PIMA View, versão 3.1 .

Nas análises geoquímicas a determinação dos óxidos de silício $\left(\mathrm{SiO}_{2}\right)$, alumínio $\left(\mathrm{Al}_{2} \mathrm{O}_{3}\right)$, ferro $\left(\mathrm{Fe}_{2} \mathrm{O}_{3}\right)$, magnésio $(\mathrm{MgO})$ e cálcio $(\mathrm{CaO})$, foram feitas com o espectrômetro de absorção atômica (EAA) marca PERKIN ELMER, modelo 603, e um espectrômetro de emissão atômica com fonte de plasma da marca Spectro Analytical Instruments GmBH, modelo Spectroflame-Fvmo3, utilizando nebulizador Meinhard. Na análise da matéria orgânica foi utilizado o método termogravimétrico.

\section{MINERALOGIA E COMPOSIÇÃO QUÍMICA DOS CARBONATOS AMOSTRADOS Petrografi-} camente, os calcários do membro médio (ou unidade C2) foram separados em quatro grupos: calcilutitos, calcarenitos, calcários oolíticos e calcários argilosos, que apesar da similaridade química, apresentaram pequenas variações espectrais. Os calcários possuem como componente ortoquímico a micrita e a esparita, podendo apresentar-se parcialmente recristalizados. Como com- 


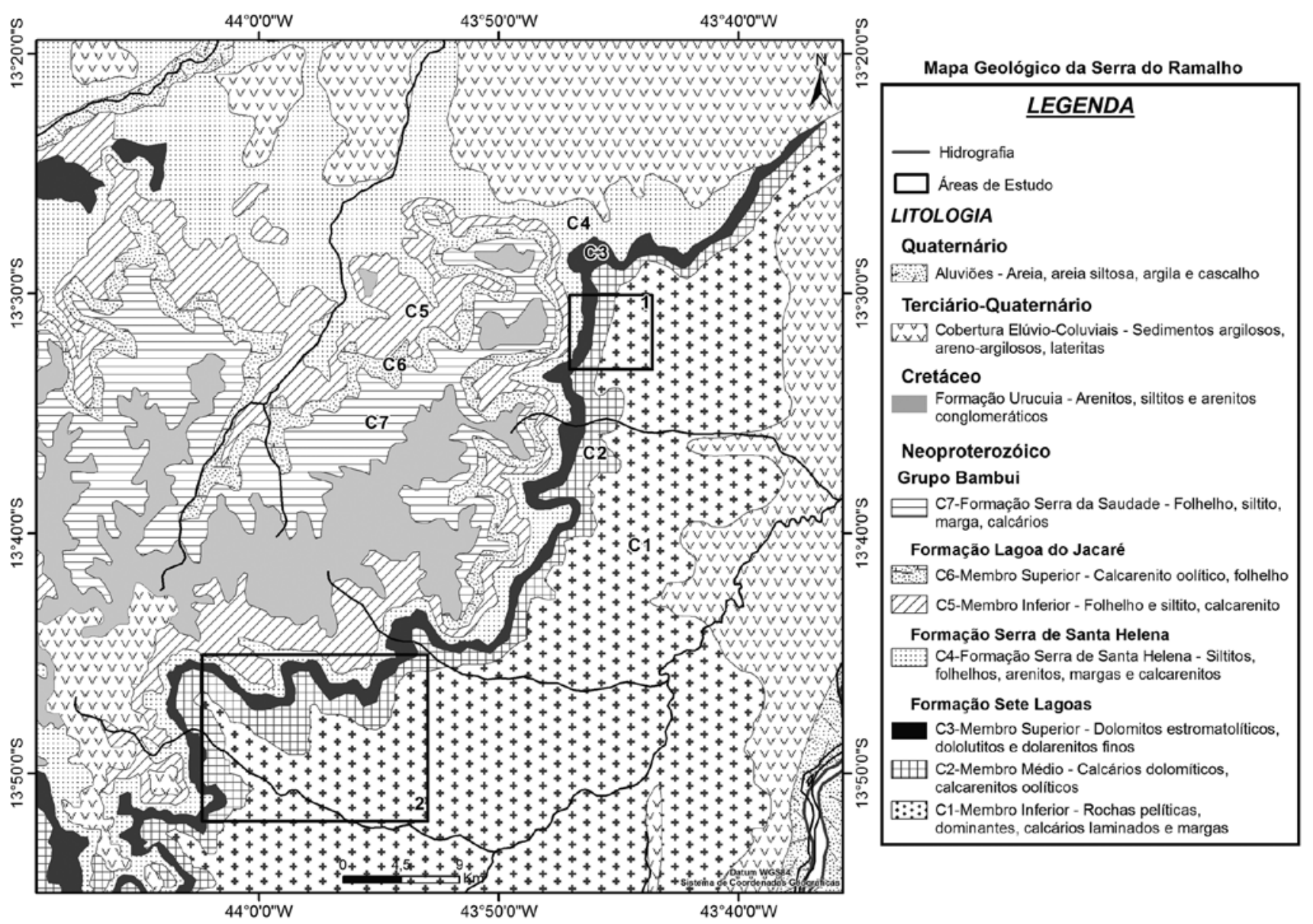

Figura 1 - Mapa Geológico da região da serra do Ramalho, Bahia (Modificado de Conceição Filho et al. 2003).

ponentes aloquímicos ocorrem intraclastos micríticos, oólitos e oncólitos. Os intraclastos podem ter formas arredondadas ou alongadas, variando de acordo com o grau de preservação. Em alguns calcários foi observada a presença de estilólitos, de minerais opacos e de veios irregulares de calcita.

Quimicamente, os calcários são bastante similares entre si e apresentam teores médios de $53 \%$ de $\mathrm{CaO}$ e de $6,0 \%$ de $\mathrm{MgO}$, exceto para duas amostras (S44 e $\mathrm{S} 123$ ), que apresentaram teores médios de $36 \%$ de $\mathrm{CaO}$ e $13 \%$ de $\mathrm{MgO}$. Os demais óxidos apresentaram teores médios de $2,5 \%$ de $\mathrm{SiO}_{2}, 0,61 \%$ de $\mathrm{Al}_{2} \mathrm{O}_{3}$ e $0,33 \%$ de $\mathrm{Fe}_{2} \mathrm{O}_{3}$, exceto a amostra $\mathrm{S} 123$ que apresentou teor mais alto, com $12 \%$, de $\mathrm{SiO}_{2}, 1,42 \%$ de $\mathrm{Al}_{2} \mathrm{O}_{3}$ e $1,3 \%$ de $\mathrm{Fe}_{2} \mathrm{O}_{3}$ e a amostra $\mathrm{S} 89 \mathrm{~A}$ com teores de $1,72 \%$ de $\mathrm{Al}_{2} \mathrm{O}_{3}$ e $0,8 \%$ de $\mathrm{Fe}_{2} \mathrm{O}_{3}$ (Tab. 1).

Os dolomitos do membro superior (ou unidade C3) são normalmente de cor cinza claro, com granulação variando de fina a média e superfícies de dissolução menos intensas. Apresentam como componente ortoquímico a micrita, geralmente bem preservada, podendo apresentar-se parcialmente recristalizada. Como componentes aloquímicos ocorrem intraclastos micríticos e esparíticos com formas arredondadas ou alongadas. Em alguns dolomitos foi observada a presença de estilólitos, e de veios irregulares de calcita. Quimicamente, são similares entre si e apresentam teores mé- dios de $42 \%$ de $\mathrm{CaO}$ e de $17 \% \mathrm{MgO}$. No limite mínimo de detecção do espectrômetro, somente a amostra S147 contém $\mathrm{SiO}_{2}$ superior a $3 \%$, e teores médios um pouco mais elevados que a média com $1,0 \%$ de $\mathrm{Al}_{2} \mathrm{O}_{3}$ e 0,69 $\%$ de $\mathrm{Fe}_{2} \mathrm{O}_{3}$ (Tab. 2).

As amostras de calcilutitos e calcarenitos selecionadas para análise de matéria orgânica foram as de cores mais escuras e que apresentavam espectros muito ruidosos. Para os dolomitos foram selecionadas duas amostras, uma cor cinza claro (S32A) e outra cinza mais escuro (S114). Os resultados obtidos permitiram a identificação de dois grupos de valores: i) um com teor de matéria orgânica inferior a $0,1 \%$; e ii) outro com teor superior a $0,1 \%$ (Tab. 3 ).

MEDIDAS ESPECTRORRADIMÉTRICAS Os espectros de reflectância foram obtidos de amostras de mão utilizando o espectrorradiômetro PIMA (Portable Infrared Mineral Analyser), que coleta dados na faixa do infravermelho de ondas curtas entre 1300 - 2500 nm, utilizando uma fonte de luz interna. Cada amostra foi medida em todas as suas faces (fresca e exposta), com o cuidado de observar as diferenças associadas às variações texturais, especialmente de micro-relevo, na resposta espectral. Para cada amostra foram feitas cerca de cinco medidas e posteriormente feito uma média. Devido à cor cinza escuro da maioria das amostras de 
Tabela 1 - Composição química, por absorção atômica, dos principais tipos de calcários do membro médio da Formação Sete Lagoas (em porcentagem e $L Q=$ limite de detecção).

\begin{tabular}{l|c|c|c|c|c|l}
\hline Amostras & $\mathrm{SiO}_{2}$ & $\mathrm{Al}_{2} \mathrm{O}_{3}$ & $\mathrm{Fe}_{2} \mathrm{O}_{3}$ & $\mathrm{CaO}$ & $\mathrm{MgO}$ & \multicolumn{1}{|c}{ Nome } \\
\hline S123 & 12,68 & 1,42 & 1,35 & 30,24 & 15,29 & Calcilutito bandado \\
\hline S56A & $<$ LQ & 0,27 & 0,26 & 54,61 & 1,54 & Calcilutito cinza escuro com intercalações de calcita \\
\hline S113 & $<$ LQ & 0,27 & 0,12 & 55,61 & LQ & Calcilutito cinza escuro com níveis de calcita recristalizada \\
\hline S94 & 1,28 & 0,45 & $<$ LQ & 54,37 & $<$ LQ & Calcilutito cinza escuro, fino \\
\hline S54 & 1,53 & 0,60 & 0,11 & 54,41 & $<$ LQ & Calcilutito cinza escuro \\
\hline S47 & LQ & 0,40 & 0,16 & 55,09 & 1,28 & Calcarenito intraesparítico grosso \\
\hline S51 & 1,89 & 0,40 & 0,30 & 53,06 & $<$ LQ & Calcarenito esparítico com fluorita \\
\hline S48 & LQ & 0,39 & $<$ LQ & 55,17 & $<$ LQ & Calcarenito cinza escuro \\
\hline S30 & 2,21 & 0,42 & 0,15 & 50,66 & 4,02 & Calcarenito intramicrítico cinza \\
\hline S125 & $<$ LQ & 0,58 & 0,18 & 55,75 & $<$ LQ & Calcarenito cinza \\
\hline S58 & 1,19 & 0,82 & 0,20 & 73,64 & $<$ LQ & Calcarenito cinza escuro, fino \\
\hline S48B & 0,76 & 0,48 & 0,19 & 56,88 & $<$ LQ & Calcarenito intraesparítico com oóides médio \\
\hline S29 & 1,19 & 0,39 & 0,34 & 54,04 & $<$ LQ & Calcarenito intramicrítico com oóides \\
\hline S44 & 1,08 & 0,54 & 0,23 & 43,07 & 11,79 & Calcarenito intramicrítico com oóides cinza escuro \\
\hline S95 & 1,25 & 0,56 & 0,18 & 52,56 & 3,23 & Calcário argiloso bandado \\
\hline S89A & 3,03 & 1,72 & 0,87 & 51,13 & 5,02 & Calcário argiloso cinza esverdeado \\
\hline Média & 2,55 & 0,61 & 0,33 & 53,14 & 6,02 & Calcários \\
\hline
\end{tabular}

Tabela 2 - Composição química, por absorção atômica, dos principais tipos de dolomitos dos membros médio e superior da Formação Sete Lagoas (em porcentagem e $L Q=$ limite de detecção).

\begin{tabular}{l|c|c|c|c|c|l}
\hline Amostras & $\mathrm{SiO}_{2}$ & $\mathrm{Al}_{2} \mathrm{O}_{3}$ & $\mathrm{Fe}_{2} \mathrm{O}_{3}$ & $\mathrm{CaO}$ & $\mathrm{MgO}$ & \multicolumn{1}{|c}{ Nome } \\
\hline $\mathrm{S} 147$ & 3,21 & 1,04 & 0,69 & 34,27 & 18,61 & $\begin{array}{l}\text { Dolarenito } \\
\text { cinza claro }\end{array}$ \\
\hline $\mathrm{S} 51 \mathrm{~A}$ & $<\mathrm{LQ}$ & 0,56 & 0,35 & 36,08 & 18,35 & $\begin{array}{l}\text { Dolalutito } \\
\text { cinza claro }\end{array}$ \\
\hline $\mathrm{S} 32 \mathrm{~A}$ & $<\mathrm{LQ}$ & 0,48 & 0,19 & 33,27 & 20,29 & $\begin{array}{l}\text { Dolalutito } \\
\text { cinza claro }\end{array}$ \\
\hline $\mathrm{S} 114$ & $<\mathrm{LQ}$ & 1,10 & 0,28 & 63,92 & 12,28 & $\begin{array}{l}\text { Dolarenito } \\
\text { cinza }\end{array}$ \\
\hline Média & 3,21 & 0,8 & 0,37 & 41,88 & 17,38 & Dolomitos \\
\hline
\end{tabular}

calcários foi necessário realizar várias medidas variando o fator de integração do instrumento, com o objetivo de obter espectros menos ruidosos.

Do total de 55 amostras medidas, de calcários e dolomitos, selecionou-se vinte amostras com base nas diferenças que apresentavam em termos de petrografia, análises química e espectral, as quais correspondem às amostras relacionadas nas tabelas $1 \mathrm{e} 2$. Para determinar os valores de profundidade, largura e a intensidade das feições de absorção que indicam as variações de composição dos carbonatos foi utilizado o programa PIMA View, cujos valores médios estão apresentados na tabela 4. No intervalo de comprimento de onda entre 1300 - $2500 \mathrm{~nm}$ todas as feições espectrais de absorção são de movimentos moleculares vibracionais, ocasionados por transições dos níveis energéticos que ocorrem entre as ligações que unem os átomos da molécula.

Particularmente, a mineralogia primária das rochas carbonáticas tem suas feições principais de ab-
Tabela 3 - Conteúdo de matéria orgânica (em porcentagem).

\begin{tabular}{l|l|l}
\hline Amostra & $\begin{array}{l}\text { Matéria } \\
\text { Orgânica }\end{array}$ & Nome \\
\hline S123 & 0,04 & Calcilutito bandado \\
\hline S54 & 0,16 & Calcilutito cinza escuro \\
\hline S113 & 0,14 & $\begin{array}{l}\text { Calcilutito cinza escuro com níveis } \\
\text { de calcita recristalizada }\end{array}$ \\
\hline S94 & 0,76 & Calcilutito cinza escuro, fino \\
\hline S125 & 0 & Calcarenito cinza \\
\hline S58 & 0 & Calcarenito cinza escuro, fino \\
\hline S47 & 0,06 & Calcarenito intraesparítico grosso \\
\hline S44B & 0,07 & $\begin{array}{l}\text { Calcarenito intramicrítico com } \\
\text { oóides médio }\end{array}$ \\
\hline S48B & 0,13 & $\begin{array}{l}\text { Calcarenito intraesparítico com } \\
\text { oóides médio }\end{array}$ \\
\hline S89A & 0,03 & Calcário argiloso cinza esverdeado \\
\hline S32A & 0,02 & Dolalutito cinza claro \\
\hline S114 & 0,02 & Dolarenito cinza \\
\hline
\end{tabular}

Tabela 4 - Características espectrais médias das feições de absorção de amostras de calcilutitos, calcarenitos, calcários oolíticos, calcários argilosos e dolomitos.

\begin{tabular}{l|l|l|l|l}
\hline Médias & $\begin{array}{l}\text { Feição de } \\
\text { Absorção } \\
\text { Principal }(\mathrm{nm})\end{array}$ & $\begin{array}{l}\text { Feição Absorção } \\
(\mathrm{nm})\end{array}$ & Profundidade & Largura \\
\hline Calcilutito & 2335 & 220019321450 & 1,09 & 54,70 \\
\hline Calcarenito & 2336 & 216219341450 & 1,62 & 45,54 \\
\hline $\begin{array}{l}\text { Calcário } \\
\text { Oolítico }\end{array}$ & 2332 & 1930 & 0,98 & 45,26 \\
\hline $\begin{array}{l}\text { Calcário } \\
\text { Argiloso }\end{array}$ & 2336 & $\begin{array}{l}215419921930 \\
1414\end{array}$ & 9,47 & 46,27 \\
\hline Dolomito & 2321 & $\begin{array}{l}245021471930 \\
1430\end{array}$ & 3,56 & 42,68 \\
\hline
\end{tabular}


sorção limitadas ao intervalo de comprimento de onda de 2000 a $2500 \mathrm{~nm}$. Nos espectros obtidos verificou-se que as feições de absorção e o padrão das curvas de reflectância são essencialmente controlados pela presença do íon $\mathrm{CO}_{3}^{-2}$, pelo conteúdo de matéria orgânica e, secundariamente, pela presença de argilominerais. Variações texturais de granulometria também exercem influência no nível de reflectância média e na intensidade das bandas de absorção. Na figura 2 são mostrados os espectros, identificados pela numeração das amostras e por traçado de tipos de linhas de acordo com a faciologia dos carbonatos: calcilutitos, calcarenitos, calcários oolíticos, calcários argilosos e dolomitos.

ANÁLISE DOS ESPECTROS Nos espectros apresentados graficamente na figura 2 observam-se as feições de absorção dos calcilutitos, calcarenitos, calcários oolíticos, calcários argilosos e dolomitos. Os dados referentes às características destas feições de absorção estão na tabela 4.

$\mathrm{Na}$ figura 2 verifica-se que as curvas espectrais dos calcilutitos mostram um comportamento padrão formado por patamares planos, com pouca variação entre as amostras. A feição principal de absorção do íon $\mathrm{CO}_{3}^{-2}$ é assimétrica e tem seu pico médio centrado em $2335 \mathrm{~nm}$ e profundidade média de 1,09 . Outras feições de menor intensidade ocorrem em $2200 \mathrm{~nm}, 1930 \mathrm{~nm}$ e em $1450 \mathrm{~nm}$. A forma das curvas espectrais dos calcarenitos é bastante similar a dos calcilutitos e mostra um comportamento padrão formado por patamares planos e com pouca variação entre as amostras. A feição principal de absorção do íon $\mathrm{CO}_{3}^{-2}$ é aberta, assimétrica e tem seu pico médio deslocado para $2336 \mathrm{~nm}$ e profundidade média de 1,62. Outras feições de menor intensidade ocorrem em $2100 \mathrm{~nm}$ e $1930 \mathrm{~nm}$ e em $1450 \mathrm{~nm}$. Nos calcários oolíticos a forma das curvas espectrais mostra igualmente um comportamento padrão formado por patamares planos, com pouca variação entre as amostras. A feição principal de absorção do íon $\mathrm{CO}_{3}^{-2}$ dos calcários oolíticos é assimétrica e tem seu pico médio centrado em $2332 \mathrm{~nm}$ e profundidade média de 0,98. Outra feição de absorção de menor intensidade ocorre em $1930 \mathrm{~nm}$. A forma da curva espectral dos calcários argilosos mostra um padrão distinto dos calcários anteriores, o que é devido à maior intensidade das feições de absorção. A feição principal de absorção do íon $\mathrm{CO}_{3}^{-}$ 2 é assimétrica, tem seu pico médio centrado em 2336 $\mathrm{nm}$ e profundidade média de 9,47. As outras feições de absorção que ocorrem em $2100 \mathrm{~nm}, 1990 \mathrm{~nm}, 1930$ $\mathrm{nm}$, e $1410 \mathrm{~nm}$ são também mais definidas que as dos outros tipos de calcário. Quanto aos dolomitos, a forma curva espectral é bastante similar à dos calcilutitos, calcarenitos e calcários oolíticos exibindo um comportamento padrão formando por patamares planos e com pouca variação entre as amostras. A feição principal de absorção do íon $\mathrm{CO}_{3}^{-2}$ é aberta, assimétrica e tem seu pico médio centrado em $2321 \mathrm{~nm}$ com profundidade média de 3,56 , portanto em posição e profundidade espectral bem distinta dos calcários calcíticos. As outras feições de menor intensidade ocorrem praticamente nas mesmas posições dos calcários, centradas em $2450 \mathrm{~nm}$, $2140 \mathrm{~nm}, 1930 \mathrm{~nm}$, e $1430 \mathrm{~nm}$.

Na figura 3 verifica-se que a presença de matéria orgânica, em quantidade maior que $0,5 \%$ nas amostras analisadas, causa uma redução da reflectância, mascarando total ou parcialmente algumas das feições de absorção, como para as amostras S94 e S54 de calcilutito e a SP48B de calcário oolítico, respectivamente
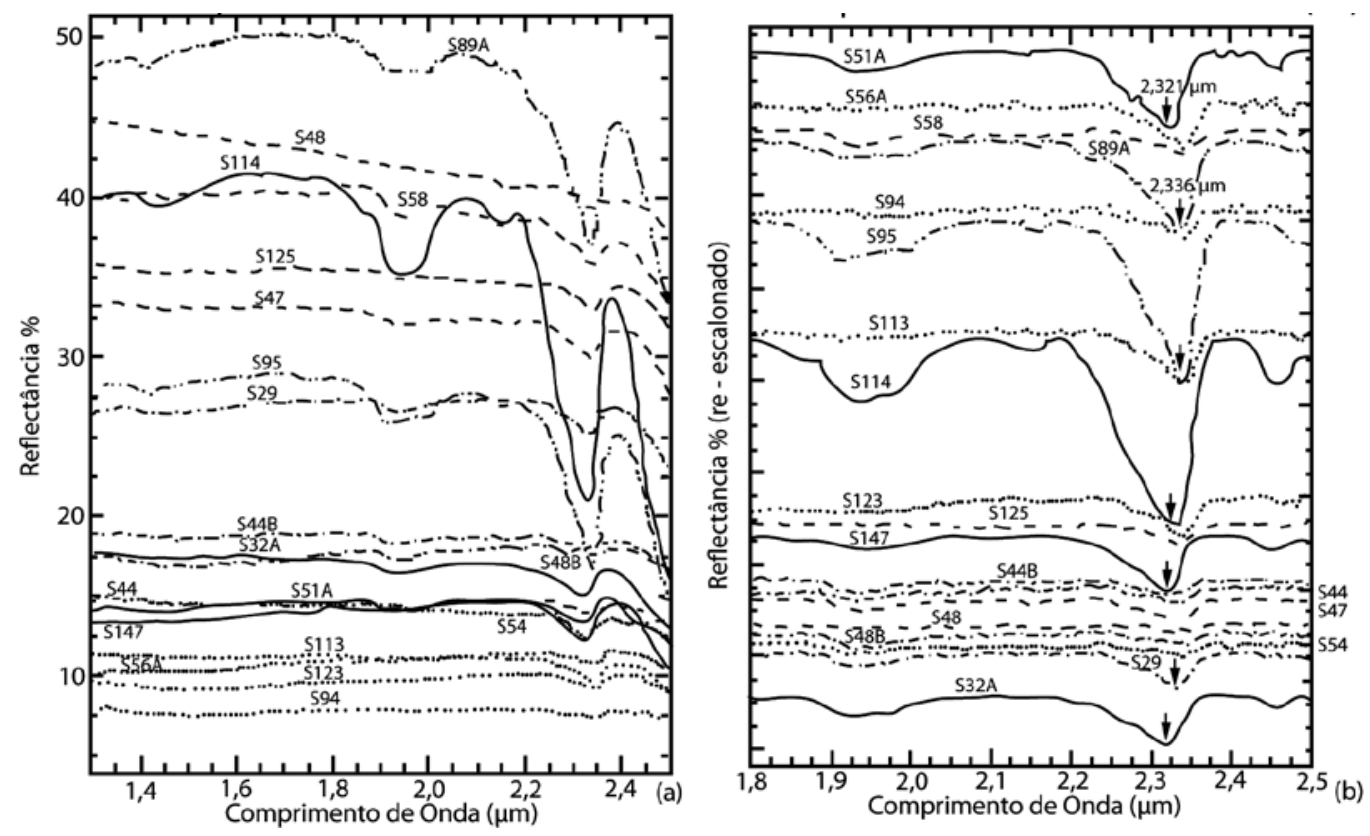

Legenda

- S51A-Dolomito

... S56A-Calcilutito

-- S58-Calcarenito

-- S89A - Calcário Argiloso

... $\$ 94$-Calcilutito

--. S95 - Calcário Argiloso

... S113-Calcilutito

- S114-Dolomito

... S123-Calcilutito

-- S125-Calcarenito

- S147-Dolomito

.-- S44B - Calcário Oolítico

-.- S44-Calcário Oolítico

-- 547 -Calcarenito

-- S48-Calcarenito

--- S48B - Calcário Oolítico

... S54-Calcilutito

-- S29-Calcário Oolítico

- S32A - Dolomito

Figura 2 - (a) Curvas espectrais dos calcilutitos, calcarenitos, calcários ooliticos, calcários argilosos e dolomitos sem remoção e (b) com remoção do contínuo (RC). 


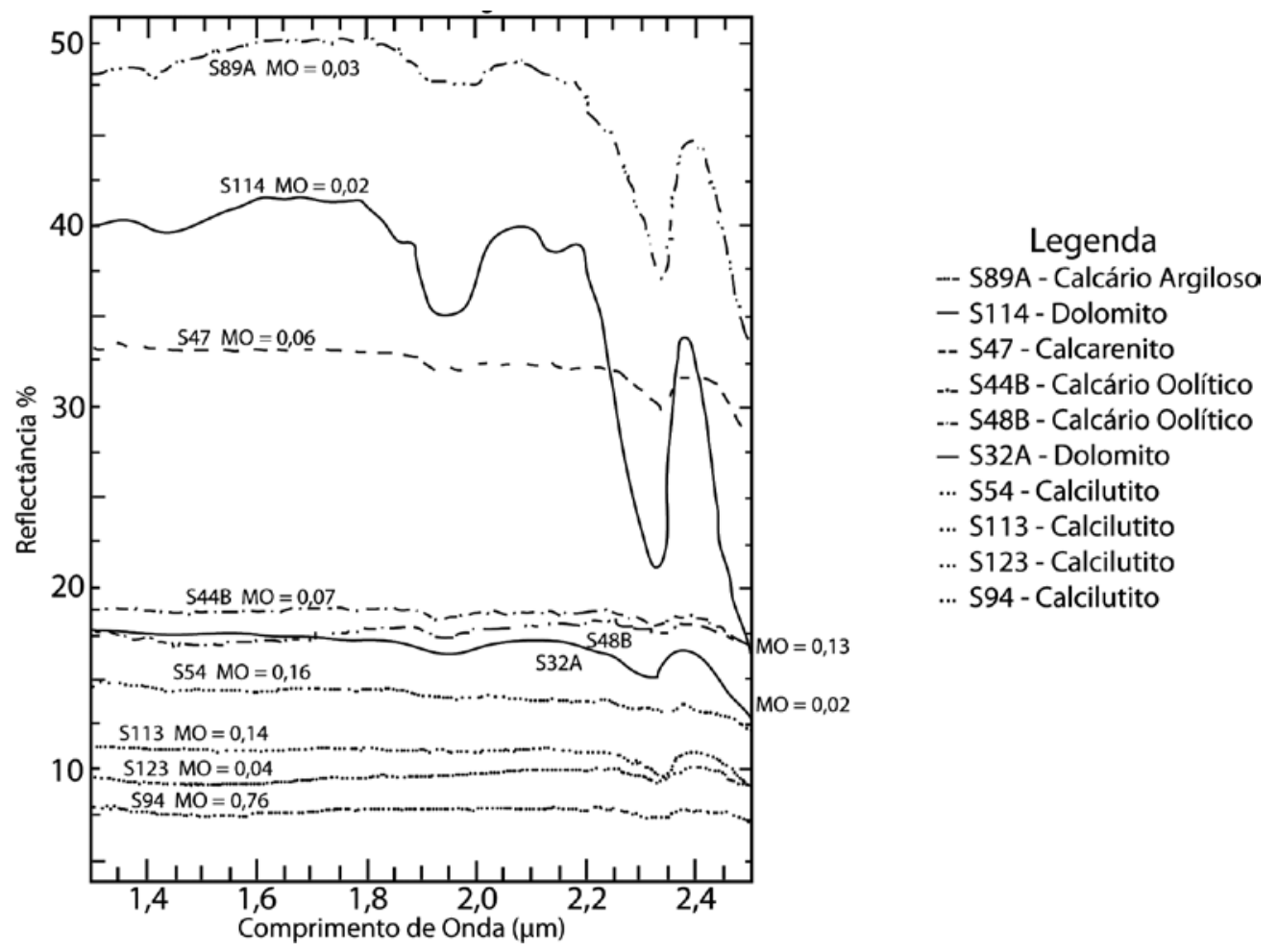

Figura 3 - Conteúdo de matéria orgânica (em porcentagem).

com $0,76 \% 0,16 \%$ e $0,13 \%$ de matéria orgânica. Entre as amostras analisadas, os calcilutitos e calcários oolíticos apresentaram teores maiores para matéria orgânica quando comparados aos dolomitos. As amostras S32A $(0,02 \%)$ e $\mathrm{S} 123(0,04 \%)$ apresentaram baixa reflectância embora tenham baixo conteúdo de matéria orgânica. Este rebaixamento pode ser explicado pela presença de minerais opacos nestas amostras, que causa a redução da reflectância.

DISCUSSÃO DOS RESULTADOS Comparando os resultados obtidos pela caracterização espectral dos diferentes tipos de calcários verificou-se que estes invariavelmente apresentam espectros ruidosos, o que não impede a detecção da feição principal de absorção do íon $\mathrm{CO}_{3}^{-2}$ centrada em $2335 \mathrm{~nm}$ nos calcilutitos, $2336 \mathrm{~nm}$ nos calcarenitos e nos calcários argilosos, e $2332 \mathrm{~nm}$ nos calcários oolíticos. Estes pequenos deslocamentos do centro das absorções podem ter sua origem nos pequenos defeitos internos dos grãos de calcita. As outras feições de absorção ocorrem com algumas variações em torno dos comprimentos de onda $2200 \mathrm{~nm}, 1930 \mathrm{~nm}$ e $1450 \mathrm{~nm}$. O fato das bandas em $1450 \mathrm{~nm}$ e $1930 \mathrm{~nm}$ ocorrerem acompanhadas da banda $2200 \mathrm{~nm}$, é sugestivo de não serem bandas devido à presença de água em inclusão, mas associadas à presença de impurezas de minerais argilosos contendo água. A banda em $2200 \mathrm{~nm}$ é produzida pela ligação molecular Al-OH e parece não afetar a banda de absorção do carbonato e a forma geral do espectro. Analisando a profundidade das feições de absorção principal, nos calcários, verifica-se uma relação entre o aumento da profundidade da feição de absorção e o aumento na granulometria da rocha. Esta relação pode ser comprovada entre os calcilutitos e calcarenitos, que apresentam em média valores de profundidade de banda de 1,09 e 1,62, respectivamente. No entanto para os calcários oolíticos, apesar de apresentarem uma granulometria maior que estas rochas, o valor da profundidade da banda diminuiu para uma média de 0,98 . A explicação para diminuição desta profundidade está relacionada à presença de matéria orgânica nestas rochas, que atenuou as feições de absorção. As curvas espectrais dos calcários argilosos, quando comparadas aos outros tipos de calcários mostrou feições de absorção mais intensas e profundas. Os calcários argilosos apesar da granulação fina apresentaram a profundidade da feição de absorção de 9,47, a mais alta entre os espectros analisados. Parece haver uma relação deste aumento da profundidade da banda carbonática com a presença da banda da água que se mostra ser mais intensa nestes calcários o que também pode ser observado no espectro da amostra de S114 de um dolarenito.

Os espectros dos dolomitos geralmente não são ruidosos, e apresentam a feição principal de absorção do íon $\mathrm{CO}_{3}^{-2}$ centrada em média em torno de $2321 \mathrm{~nm}$. Foi observada a presença de feições menores marcadas nos comprimentos de onda $2450 \mathrm{~nm}$, $2147 \mathrm{~nm}, 1930 \mathrm{~nm}$ e $1430 \mathrm{~nm}$. A banda em $2450 \mathrm{~nm}$ é muito provavelmente uma banda de carbonato, que é mais conhecida de ocorrer em $2500 \mathrm{~nm}$, no limte do comprimento de onda com o infravermelho médio. E a banda em 2147 nm é da ligação Al-OH que em argilas 
mostra quase sempre o deslocamento entre $2160 \mathrm{~nm}$ e $2230 \mathrm{~nm}$. O valor de profundidade das feições de absorção média dos dolomitos é de 3,56, que é maior que a profundidade dos diferentes tipos de calcários, exceto a dos calcários argilosos, que apresentam profundidade de 9,47. Uma comparação entre as curvas espectrais dos calcários e dos dolomitos não mostra diferença marcante entre as formas dos espectros e das larguras e assimetrias das feições de absorção. Confirmou-se, como esperado, que a principal diferença espectral é a posição da feição de absorção devido ao íon $\mathrm{CO}_{3}{ }^{-2}$, dos minerais primários de calcita e dolomita, respectivamente em $2335 \mathrm{~nm}$ e $2321 \mathrm{~nm}$.

A presença de matéria orgânica, que constitui impureza na composição mineralógica da rocha, tende a decrescer a reflectância e o albedo das curvas espectrais, mesmo para baixos teores de matéria orgânica. Os calcilutitos e os calcários oolíticos apresentaram os maiores teores de matéria orgânica, sendo esta presença marcada pela cor cinza escuro a preta destas rochas e pelos baixos valores de reflectância. A presença de opacos e matéria orgânica nos dolomitos (amostra S32A), mesmos com teores baixos, proporcionou uma redução no albedo de suas curvas espectrais.
CONCLUSÃO Na região do infravermelho de ondas curtas do espectro eletromagnético é possível separar, dentro do grupo das rochas carbonáticas, os calcários dos dolomitos. Apesar de existir certa similaridade espectral entre estas rochas, a principal feição de absorção dos dolomitos é bem definida e está em torno $2321 \mathrm{~nm}$, enquanto em média os calcários apresentam a feição de absorção principal em $2335 \mathrm{~nm}$. Entre as rochas carbonáticas observa-se um deslocamento da principal feição de absorção dos calcários oolíticos quando comparado aos demais, não apresentando a feição secundária em $1400 \mathrm{~nm}$. A presença de impurezas de matéria orgânica, em algumas amostras mostrou uma redução da profundidade das bandas de absorção e do albedo espectral. Os calcários da Formação Sete Lagoas invariavelmente apresentam espectros de reflectância ruidosos, ao contrário dos dolomitos, cujos espectros são sempre limpos. O uso da espectrorradiometria mostra ser um instrumento de análise que apresenta um rápido resultado sobre a composição principal das rochas carbonáticas e de pequenas impurezas minerais, fornecendo os dados necessários para se determinar a resolução espectral de sensores imageadores para o mapeamento litológico.

\section{Referências}

Clark R.N., King V.V.T., Klejwa, M., Swayze G.A., Vergo N. 1990. High spectral resolution reflectance spectroscopy of minerals. Journal of Geophysical Research, 95(B8): 12653-12680.

Conceição Filho V.M., Monteiro D.M., Rangel P. de A., Garrido I.A.de A. 2003. Bacia do São Francisco entre Santa Maria da Vitória e Iuiú, Bahia: geologia e potencialidade econômica. Salvador, CBPM, 76 p. Disponível em: http:// www.cbpm.com.br/paginas/public_series_arquivos_abertos.php (volume 18). Acessado em: 24/04/2010.

Crowley J.K. 1986. Visible and near-infrared spectra of carbonate rocks: reflectance variations related to petrographic texture and impurities. Journal of Geophysical Research, 91(B5):5001-5012.

Gaffey S.J. 1986. Spectral reflectance of carbonate minerals in the visible and near Infrared $(0,35-2,55 \mu \mathrm{m})$ : Calcite, Aragonite and Dolomite. American Mineralogist, 71:151-162.

Gaffey S.J. 1987. Spectral reflectance of carbonate minerals in the visible and near infrared $(0,35-2,55 \mu \mathrm{m})$ : Anhydrous Carbonate Minerals. Journal of Geophysical Research, 90(B2):1429-1440.

Hunt G.R., Salisbury J.W. 1971. Visible and near infrared spectra of minerals and rocks: II. Carbonates. Modern Geology, 2:195-205.

Hunt G.R. \& Salisbury J.W. 1976. Visible and near infrared spectra of minerals and rocks: XI. Sedimentary Rocks. Modern Geology, 5:211-217.

Hunt G.R. 1977. Spectral signatures of particulate minerals in the visible and near infrared. Geophysics, 42(3):401-413. Hunt G.R. 1979. Near infrared (1,3-2,4 $\mu \mathrm{m})$ spectra of alteration minerals potencial for use in remote sensing. Geophysics, 44(12):1974-1986.

INTEGRATED SPECTRONICS PTY Ltd. PIMA SP Acquisition. Versão 2.2., PIMAView. Versão 3.1.

Meneses P.R. 1986. Avaliação e seleção de bandas do sensor thematic mapper do LANDSAT5 para a discriminação de rochas carbonáticas do grupo Bambuí como subsídio ao mapeamento de semidetalhe. Tese de Doutoramento, Instituto de Geociências, Universidade de São Paulo, 233 p.

Meneses P.R., Pontara R.C.P., Freitas-Silva F.H., Madeira Neto J.C. 2001a. Comportamento da reflectância espectral de filitos carbonosos mineralizados em ouro. Revista Brasileira de Geociências, 31(1):83-88.

Meneses P.R., Madeira Netto J.S. (org.) 2001b. Sensoriamento remoto: reflectância dos alvos naturais. Brasília, DF. UnB; Planaltina: Embrapa Cerrados, 262 p.

Miranda L.L.F., Monteiro M.D., Cavalcanti J.C.C., Valle C.R.O., Silva J.C. 1976. Projeto Fluorita da Serra do Ramalho. Salvador - BA, SME: CBPM, 92 p. Convênio SME/CPM-CBPM. Resumo disponível em: http://www. cbpm.com.br:80/igba/index2.asp (Projeto Fluorita). Acessado em: 24/04/2010.

Manuscrito ID 17361

Submissão: 25 de abril de 2010 Aceito em 22 de novembro de 2010 